\title{
A INVESTIGAÇÃO DOS CONHECIMENTOS PRÉVIOS SOBRE GEOMETRIA EUCLIDIANA, ESFÉRICA E HIPERBÓLICA POR MEIO DA UTILIZAÇÃO DE QUESTIONÁRIO
}

\author{
Wanderley Pivatto Brum \\ Universidade Regional de Blumenau \\ Mestrando em Ensino de Ciências Naturais e Matemática \\ Rua Antônio da Veiga, 140, Victor Konder, 89012-900 - Blumenau (SC) \\ ufsc2013@yahoo.com.br \\ Elcio Schuhmacher \\ Universidade Regional de Blumenau \\ Dr. em Química pela Universidade Federal de Santa Catarina (Conceito Capes 7) \\ Rua Antônio da Veiga, 140, Victor Konder, 89012-900 - Blumenau (SC) \\ elcio@furb.br
}

\section{RESUMO}

A presente investigação consiste na identificação dos conhecimentos prévios sobre Geometria Euclidiana, Esférica e Hiperbólica, em estudantes da $2^{\text {a }}$ série do Ensino Médio de uma escola da rede pública de Tijucas, Santa Catarina. Para o reconhecimento das referidas concepções, foi utilizado um questionário semiestruturado, favorecendo a exposição de ideias por meio de textos e desenhos. O pensamento sobre aprendizagem significativa estudada por Ausubel e seus colaboradores foi o aporte teórico utilizado para reflexões e discussões a partir dos dados coletados. $\mathrm{O}$ estudo revelou diversas lacunas e fragilidades conceituais nas concepções dos estudantes sobre geometria.

Palavras-Chave: conhecimentos prévios; geometria euclidiana; esférica; hiperbólica; questionário.

\section{A PRELIMINARY INVESTIGATION OF KNOWLEDGE ABOUT EUCLIDEAN GEOMETRY, SPHERICAL AND HYPERBOLIC THROUGH USE OF QUESTIONNAIRE}

\begin{abstract}
This research is the identification of prior knowledge about Euclidean, Spherical and Hyperbolic, students in the 2nd grade of secondary education at a school of public Tijucas, Santa Catarina. For the recognition of these concepts, we used a semi-structured questionnaire, favoring exposure of ideas through texts and drawings. Thinking about meaningful learning studied by Ausubel and colleagues was used for the theoretical reflections and discussions from the data collected. The study revealed several conceptual gaps and weaknesses in students' conceptions about geometry. Keywords: previous knowledge; Euclidean geometry, spherical, hyperbolic questionnaire.
\end{abstract}

\section{INTRODUÇÃO}

Nas duas últimas décadas, houve uma intensa discussão nos meios educacionais, por parte dos membros de associações de profissionais da Matemática (KALLEFF, 2004), (CABARITI, 2006), (ALVES, 2008), (BONGIOVANI，2010), (CARVALHO，2011), (CEDREZ，2012), 


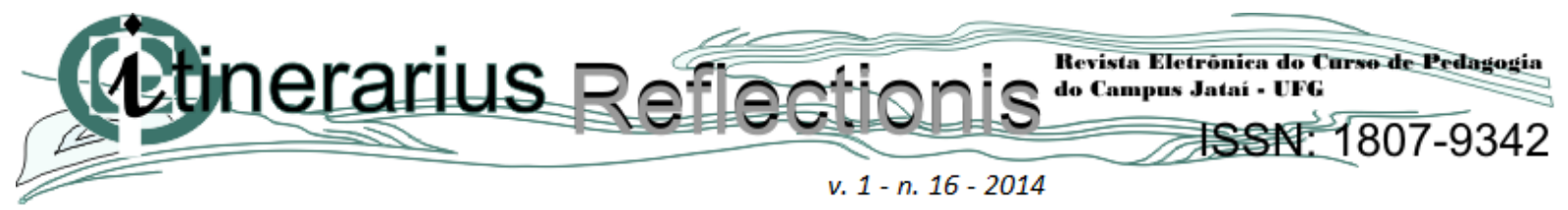

(LEIVAS, 2012) e (MARTOS, 2012) para a inclusão de conteúdos, advindos da Geometria Euclidiana, como a Geometria Esférica e Hiperbólica nos bancos escolares, considerada como adequado à formação de estudantes para o século XXI, em decorrência dos avanços teóricos da Matemática e da Computação. Dessas discussões, emergiram alguns questionamentos: $\mathrm{O}$ ensino da Geometria não Euclidiana é um tema distante da realidade dos estudantes? O modelo geométrico para representar o planeta Terra abordado nas aulas de Geografia e Matemática é um plano, uma folha retangular ou uma superfície quase esférica? Se um dos pontos de discussão é a reformulação do ensino no Brasil, porque as Geometrias não Euclidianas ainda não são consideradas um ramo importante da Matemática por parte dos professores? Será que o ensino de Geometrias não Euclidianas, como a Esférica e Hiperbólica vem causando inquietações em professores de Matemática, por ser um assunto novo e ainda desconhecido?

A busca de respostas para estas questões demonstra além de sua importância, a necessidade de divulgação junto aos professores desse conteúdo ainda pouco explorado em sala de aula, afinal, nos dias atuais, naves espaciais, por exemplo, percorrem em suas viagens, trajetórias que não são retilíneas e segundo (EVES, 2008), (BOYER, 2009), (MLODINOW, 2010), existem registros que indicam o medo de alguns navegadores, por acreditarem que ao fim do horizonte, os navios eram engolidos ou chegaria ao "fim do mundo". Este pensamento era devido à interpretação que muitas pessoas atribuíam ao formato da Terra.

É possível encontrar ainda alguns estudantes que representam geometricamente o planeta por meio de um plano, e não é difícil comprovar tal afirmação, basta observar que ao demonstrar o comportamento da gravidade sobre os seres humanos, evidenciam modelos euclidianos em detrimento a modelos esféricos, hiperbólicos e até elipsóidicos. A Geometria é um dos temas mais interessantes para serem explorados pelos professores, por se constituir de uma riqueza em ilustrações, por possibilitar resoluções diversas com criatividade, e por fim, proporcionar aos estudantes uma interação mais dinâmica com o conhecimento. Uma das justificativas para esta afirmação é a existência de discussões acerca da inserção de Geometria Esférica e Hiperbólica nos currículos escolares quem se encontram nos Parâmetros Curriculares Nacionais de Matemática (BRASIL, 1998), os quais apresentam a importância do ensino de outras geometrias, aos estudantes:

[...] a Matemática não evolui de forma linear e logicamente organizada. Desenvolve - se com movimentos de idas e vindas, com rupturas de paradigmas. Frequentemente um conhecimento é amplamente utilizado na ciência ou na tecnologia antes de ser incorporado a um dos sistemas lógicos formais do corpo da Matemática. Exemplos desse fato podem ser 


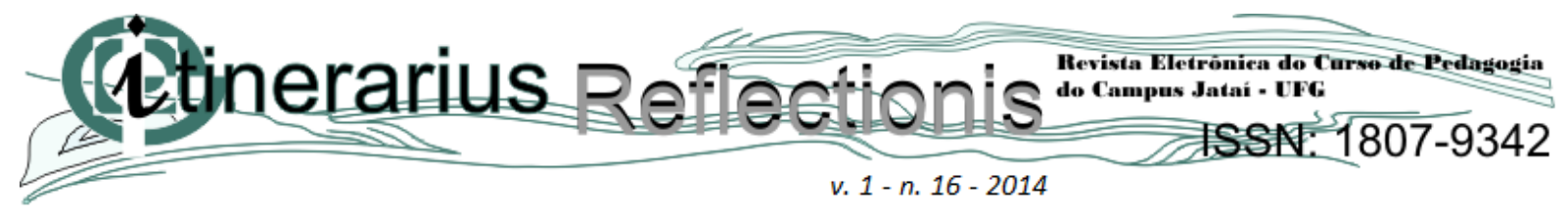

encontrados no surgimento dos números negativos, irracionais e imaginários. Uma instância importante de mudança de paradigma ocorreu quando se superou a visão de uma única geometria do real, a Geometria Euclidiana, para aceitação de uma pluralidade de modelos geométricos, logicamente consistentes, que podem modelar a realidade do espaço físico. (BRASIL, 1998, p. 24, grifo nosso).

Neste sentido, os PCN (Parâmetros Curriculares Nacionais) colocam que entre os objetivos do ensino de Matemática se encontra o desenvolvimento do pensamento geométrico. Recomenda-se a exploração de situações de aprendizagem que levem o estudante a resolver situações problema de localização e deslocamento de pontos no espaço, ler mapas, estimar e comparar distâncias percorridas, reconhecer propriedades de formas geométricas e saber usar diferentes unidades de medida. Portanto, há uma orientação para situações de aprendizagem que levem o estudante a estabelecer diferenças entre objetos sob diferentes pontos de vista, construindo e interpretando suas representações.

Partindo dessa breve apresentação sobre Geometria e compreendendo que o estudante deve ser o elemento ativo no processo de construção do conhecimento, o principal objetivo deste estudo é identificar os conhecimentos prévios dos estudantes sobre Geometria Euclidiana, Esférica e Hiperbólica. A investigação apresenta algumas considerações teóricas que fundamentam esta investigação que são referentes à Aprendizagem Significativa. Na sequência são apresentados os resultados e a análise tecendo comentários de ordem geral.

\section{BASES DA TEORIA DA APRENDIZAGEM SIGNIFICATIVA}

A teoria da aprendizagem significativa foi formulada inicialmente pelo psicólogo norte americano David Paul Ausubel. As ideias de Ausubel, cujas formulações iniciais são dos anos 60, se encontram entre as primeiras propostas psicoeducativas em sua obra "Psicologia Educacional", e que recebeu colaborações em 1980 de Joseph Donald Novak e Helen Hanesian, acerca de fatores sociais, cognitivos e afetivos na aprendizagem. A aprendizagem significativa é uma tentativa de fornecer sentido ou de estabelecer relações de modo não arbitrário e substancial (não ao pé da letra) entre os novos conhecimentos e os conceitos existentes. Em contraponto à aprendizagem significativa, surge a aprendizagem mecânica que para Ausubel, Novak e Hanesian (1980) é o tipo de aprendizagem diferentemente do processo significativo. Ocorre quando o estudante é apresentado a um novo conhecimento, e este, por motivos variados, não o relaciona com algum 


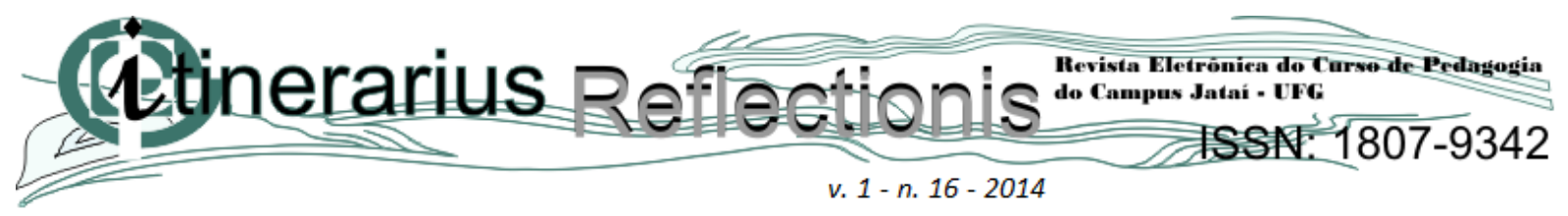

conceito que já exista em sua mente, simplesmente, é incorporado de maneira arbitrária e não substantiva.

A aprendizagem (significativa ou mecânica) pode ocorrer por meio de recepção, enfatizado por Moreira (2010), como aquela em que todo o conteúdo vai ser aprendido é apresentada ao estudante na forma final, ou por descoberta, onde os conceitos não são fornecidos, mas deve ser "descoberto" pelo estudante antes que possa ser incorporado significativamente na sua estrutura cognitiva. Em ambos os casos (recepção ou descoberta), a aprendizagem significativa ocorre quando há um processo de interação, no qual os conceitos mais relevantes e inclusivos (subsunçores) integram com o novo material a ser aprendido. A aprendizagem significativa é caracterizada por uma interação entre os aspectos específicos e relevantes da estrutura cognitiva com as novas informações, por meio das quais essas adquirem significado e são integradas a uma estrutura hierárquica, altamente organizada por subsunçores. A aprendizagem significativa deve preponderar em relação a uma aprendizagem de associações arbitrárias, organizacionalmente isoladas, mecânica, pressupondo a existência prévia de subsunçores. Para os autores, subsunçor é um conceito já existente na estrutura cognitiva, capaz de servir de ancoradouro a uma nova informação, de modo que esta adquira significado para o estudante.

Moreira e Masini (2001) defendem que para uma aprendizagem significativa ocorrer, a nova informação deve ancorar em subsunçores relevantes preexistentes na estrutura cognitiva do estudante. Pensando em aprendizagem significativa e pressupondo a existência de conceitos subsunçores, o que fazer quando eles não existirem? Neste sentido, Ausubel, Novak e Hanesian (1980), citam que a aprendizagem mecânica é necessária, sempre que o estudante adquire informação em uma área completamente nova para ele, assim, alguns elementos do conhecimento relevantes a nova informação, passam a fazer parte da sua estrutura cognitiva, servindo de subsunçor, ainda que pouco elaborado. Nesta direção, os autores descrevem que o armazenamento de informações na mente humana é altamente organizado, formado por uma hierarquia conceitual no qual, as ideias mais gerais e inclusivas do conteúdo deverão ser apresentadas no início para, somente então, serem progressivamente diferenciados em detalhes e especificidade.

Se tivéssemos que reduzir toda a psicologia educacional a um único princípio diríamos que o fator singular mais importante que influencia a aprendizagem é aquilo que o aprendiz já sabe, descubra isso e baseie nisso seus ensinamentos (AUSUBEL; NOVAK; HANESIAN, 1980, p. 137). 


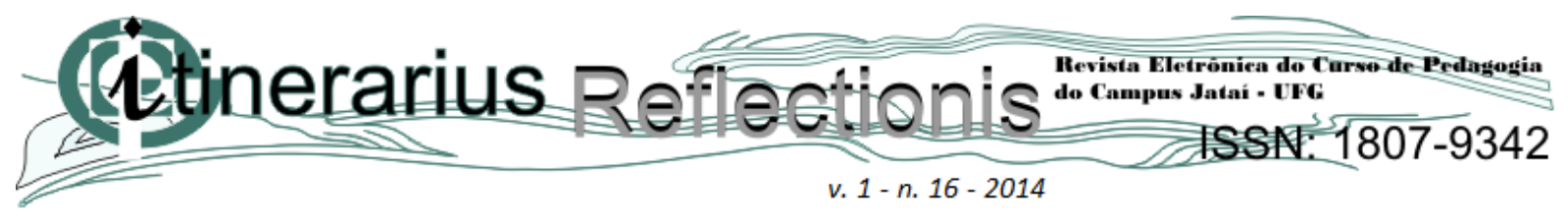

Nesta vertente, o projeto educativo do professor deve está direcionado para o desenvolvimento cognitivo dos estudantes ao priorizar seus conhecimentos prévios, reconhecido que raramente vem marcado por estudos avançados, servindo assim de ancoragem para as novas ideias e conceitos o que constitui a base fundamental para o processo de aprendizagem.

No intuito de possibilitar uma aprendizagem significativa em sala de aula, Ausubel e seus colaboradores apontam algumas condições que devem ser satisfeitas. Primeiramente, na estrutura cognitiva do estudante, devem existir, ideias relevantes (subsunçores) necessários, para que possam ser relacionados com os novos conhecimentos. Moreira (2010) entende que, o estudante deve ter algum elemento (já significativo) que possa atuar como meio de suporte, seja ele um conceito, uma imagem, uma ideia, um símbolo ou uma proposição. Em segundo, o estudante precisa ter uma disposição para aprender: se o estudante deseja memorizar o conteúdo de maneira arbitrária e literal então a aprendizagem será mecânica e em terceiro, o estudante deve ser exposto a um conteúdo escolar potencialmente significativo, ou seja, que tenha sentido lógico, sendo que as novas informações possam se relacionar com ideias básicas relevantes já construídas e disponíveis na estrutura cognitiva.

A teoria ausubeliana apresenta três tipos de aprendizagem significativa: a aprendizagem representacional, a aprendizagem conceitual (conceitos) e a proposicional (figura 1).

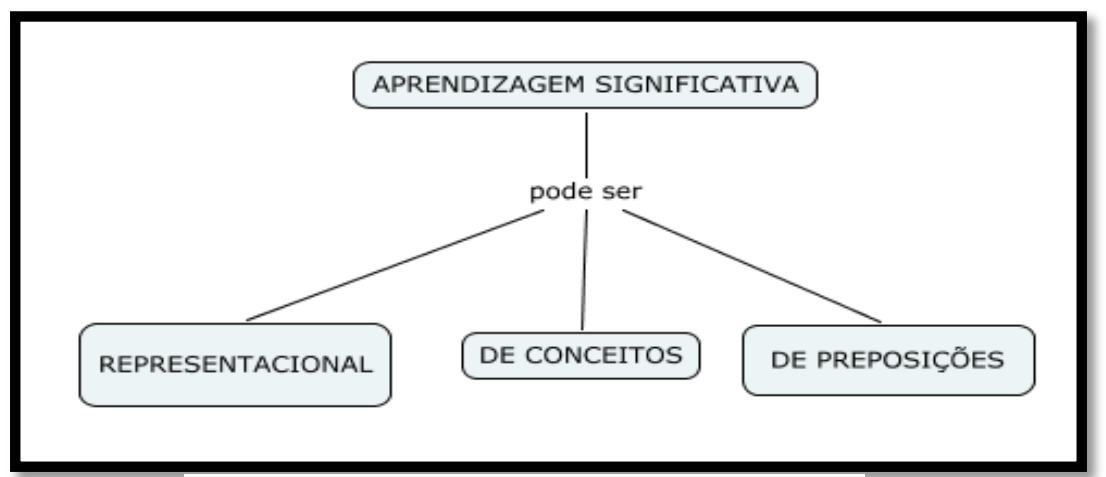

Figura 1: Tipos de aprendizagem significativa

Fonte: (AUSUBEL; NOVAK; HANESIAN, 1980, p. 47)

A representacional se refere ao significado dos símbolos unitários, a de conceitos tem sua representação por meio de símbolos, todavia são genéricos ou categóricos, enquanto a proposicional envolve uma relação entre conceitos ou significado de ideias. A aprendizagem representacional é o tipo mais básico de aprendizagem significativa. Portanto, a aquisição de vocabulário dentro de uma 


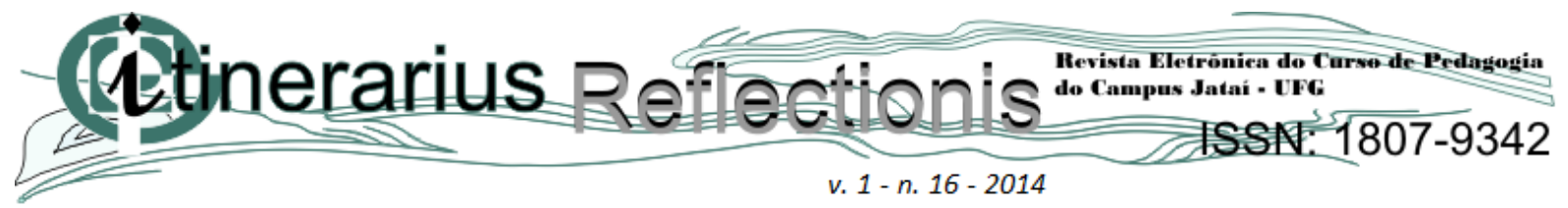

determinada língua, onde as primeiras palavras que a criança aprende são representações de objetos ou fatos reais e não categorias.

A aprendizagem representacional significa aprender o que um determinado padrão de estimulação (como, por exemplo, um padrão diferenciado de sons ou símbolos "cachorro" ou mesmo um símbolo gráfico, como um desenho ou um croqui) representa e com isso significa aproximadamente a mesma coisa (uma imagem de cachorro) significa (AUSUBEL; NOVAK; HANESIAN, 1980, p. 44).

Por exemplo, uma criança que aprende pela primeira vez o significado da palavra "cachorro", o objetivo é que o som represente, ou seja, equivalente a um objeto (cachorro) que está em observação naquele momento, e, portanto, significando a mesma imagem propriamente dita. A criança relacionará de forma não arbitrária e substantiva esta proposição ao conteúdo relevante de sua estrutura cognitiva. Após o término do processo de aprendizagem significativa, a palavra cachorro será capaz de provocar o aparecimento de uma imagem composta de vários cachorros em sua experiência. Um indivíduo num estágio primitivo de desenvolvimento, o que um determinado símbolo significa é inicialmente algo completamente desconhecido para ele, é algo que ele tem que aprender, tal processo de aprendizagem é denominado representacional (AUSUBEL; NOVAK; HANESIAN, 1980). Assim aprender a palavra "cachorro" para uma criança de um ano, significa apenas a imagem de seu próprio cachorro, contudo, para uma criança pré-escolar significa os atributos essenciais e não particulares de uma imagem genérica de cachorro.

Para os autores, o passo principal para a aprendizagem representacional é dado geralmente próximo ao fim do primeiro ano de vida, quando a criança adquire a compreensão geral de que, é possível usar o símbolo para representar qualquer significado. Aprender o significado de uma palavra exige conhecimento prévio da palavra propriamente dita, do que outras formas de aprendizagem representacional, uma vez que, aprender a palavra conceito difere essencialmente da aprendizagem do significado das palavras, que não representam conceitos. Ausubel, Novak e Hanesian (1980) enfatizam que, se um conceito é adquirido de maneira mecânica, sem que seus atributos sejam relacionados de maneira não arbitrária e substantiva à sua estrutura cognitiva, este terá pouca validade e será esquecido rapidamente. Com relação a não arbitrariedade, os autores relembram que o material em questão proporcione um caráter de não aleatoriedade, ou seja, nele deve transitar uma base adequada e quase auto evidente de modo a ser possível relacionar ideias relevantes que os estudantes são capazes de elaborar. Por outro lado, a relação substantiva prioriza 


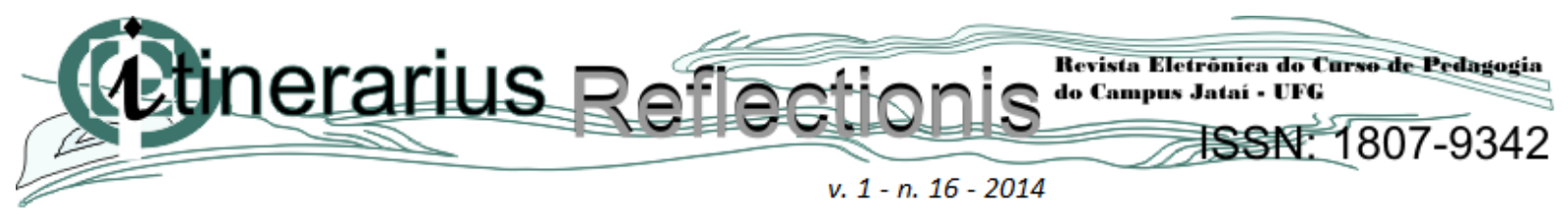

que o material de aprendizagem deve permitir que símbolo ou grupo de símbolos equivalentes, se relacione à estrutura cognitiva sem alteração no significado do conceito.

Ausubel, Novak e Hanesian (1980) definem conceito como objetos, eventos, situações que possuam atributos essenciais, comuns que são designados por algum símbolo. Existem dois métodos de aprendizagem de conceitos: primeiramente a formação de conceitos, ocorrida a partir da abstração indutiva, de experiências reais, por meio de descoberta, levado à estágios sucessivos de formulação de hipóteses e generalização. As crianças aprendem o conceito de "cachorro", por meio de encontros sucessivos com cachorros, nesse caso o símbolo "cachorro" é aprendido antes do conceito. Uma segunda maneira de aprendizagem de conceitos é a assimilação, no qual consiste em relacionar os novos conceitos com os anteriormente formados ou assimilados, já existentes na estrutura cognitiva da criança, isto é, à medida que ela cresce e entra na escola e passa a receber instrução formal, o vocabulário da criança aumenta e novos conceitos são adquiridos por meio do processo de assimilação (AUSUBEL; NOVAK; HANESIAN, 1980). Enquanto na formação de conceitos, o significado é consequência da abstração da própria realidade, na assimilação de conceitos, é extraído de uma interação da nova informação com conceitos previamente adquiridos. A tarefa de aprendizagem significativa não consiste em aprender o que as palavras representam individualmente ou combinadas, mas antes aprender o significado de novas ideias expressas, a partir de frases ou orações compostas de dois ou mais conceitos. O somatório dos significados de conceitos que compõem a proposição não terá o mesmo significado da proposição.

Para Novak, Gowin (1996) as proposições consistem, em dois ou mais termos conceituais ligados a uma unidade semântica. Pensando em uma metáfora, as proposições são "moléculas" a qual se constroem significados e os conceitos são os "átomos" do significado. Esse tipo de aprendizagem supõe que o estudante já tenha em sua estrutura cognitiva, o significado dos conceitos que compõem a proposição, entendendo que, a partir da idade escolar, ocorrerá o processo fundamental da aprendizagem ou aquisição de significados.

\section{PROCEDIMENTOS METODOLÓGICOS DA INVESTIGAÇÃO}

Com objetivo de identificar os conhecimentos prévios dos estudantes acerca de Geometria Euclidiana, Esférica e Hiperbólica foi elaborado um pré-teste formado por um questionário semiestruturado a uma classe de quatorze estudantes da segunda série do ensino médio numa escola 


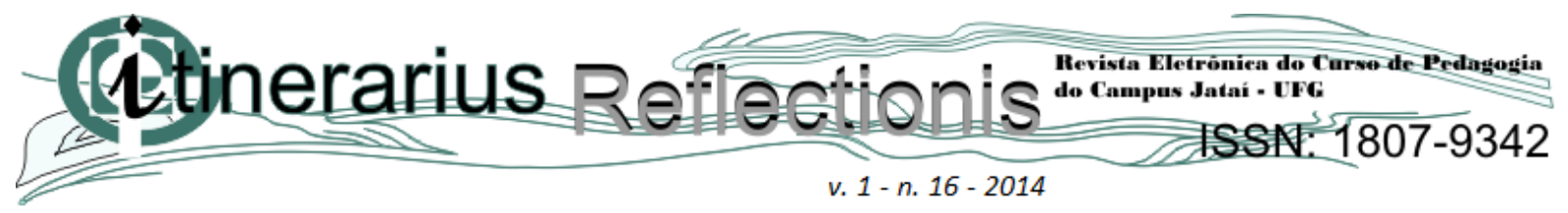

do município de Tijucas da rede pública de ensino do estado de Santa Catarina. Na elaboração do pré-teste foi eleito assuntos considerados pertinentes para a abordagem de conceitos de Geometria, como, retas paralelas, menor distância entre dois pontos, soma das medidas dos ângulos internos de um triângulo, axiomas, postulados, triângulos e quadriláteros. Para análise dos resultados foi utilizado dados percentuais para as questões fechadas e conteúdo categorial a posteriori para questões abertas que em geral busca extrair os significados explícitos e implícitos no discurso dos sujeitos.

\section{RESULTADOS DO PRÉ-TESTE}

Com a finalidade de detectar os conhecimentos prévios sobre Geometria Euclidiana, Esférica e Hiperbólica (subsunçores) presentes na estrutura cognitiva de cada estudante, as questões apresentadas no questionário foram as seguintes:

\section{Questão 01}

1. A palavra "geometria" significa:

a) O mesmo que geografia

b) Medição da "Terra" onde geo significa "terra" e metria significa "medição".

c) Matriz terrestre onde geo significa "terra" e metria significa "matriz".

d) Estudo da paisagem.

Esta questão teve como objetivo identificar se os estudantes possuíam conhecimentos prévios (subsunçores) sobre o conceito de Geometria. Acreditávamos que os estudantes por estarem no ensino médio e já terem estudado em diversos momentos do ensino fundamental o conteúdo de Geometria, assinalassem que deriva do latim, cujo significado é medição de terra (b), entretanto 64,29\% dos estudantes assinalaram corretamente, enquanto 14,29\% optaram pela alternativa (c), demonstrando não conhecer o conceito da palavra metria, confundindo com o termo matriz e $21,43 \%$ optaram pela alternativa (d), relacionando a palavra paisagem com objetos que encontramos na natureza. Por fim, nenhum dos estudantes optou pela alternativa (a). A análise desta questão evidencia para mais de um terço da turma, a ausência do significado do conceito de Geometria.

\section{Questão 02}

2. Como você vê e imagina que seja a linha do Equador, os trópicos e o meridiano de Greenwich? Desenhe a alternativa escolhida.
a) Uma linha
b) São linhas verticais e horizontais

c) São circunferências d) São elipses 


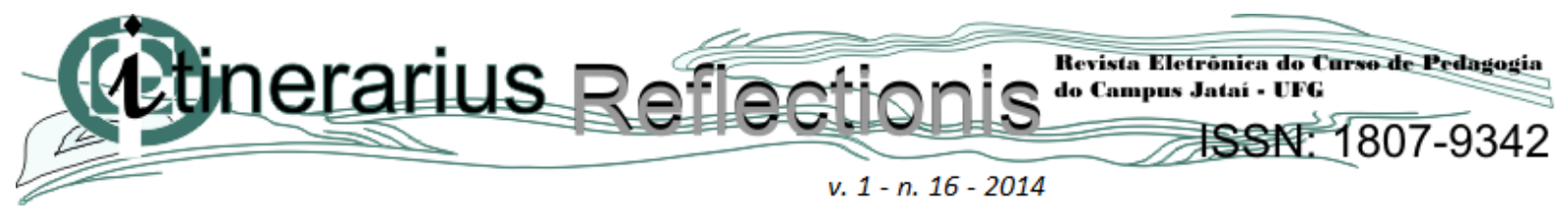

$\underline{\text { Análise }}$

Esta questão teve como objetivo, verificar como os estudantes entendem e demonstram por meio do desenho geométrico, a linha do Equador, os trópicos e os meridianos. Esperávamos que os estudantes optassem pela alternativa (d), justificado pelo fato de estudar a disciplina de Geografia e estar habituado ao modelo terrestre, por meio do globo, facilitando a resposta a esta pergunta, entretanto, apenas 14,29\% assinalaram corretamente, conforme pode ser observado no registro feito pelo estudante (11) (figura 2).

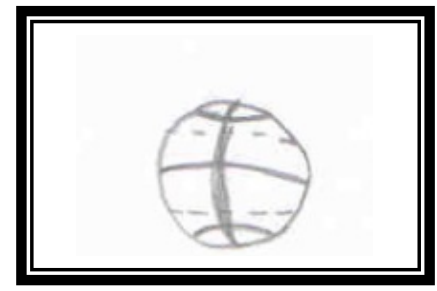

Figura 2: Protocolo do estudante 11 referente ao modelo geométrico da questão 02.

Com relação à alternativa (a), 14,29\% dos estudantes entenderam que a melhor representação são linhas imaginárias, com formas tracejadas nos paralelos e uma linha contínua para a linha do Equador sem representar os meridianos. Isto mostra como os estudantes por meio de seus conhecimentos euclidianos entendem esta questão. Outro ponto para análise é a forma representacional das linhas para representar os paralelos e meridianos. O estudante (11), por exemplo, apresentou linhas tracejadas para alguns paralelos e uma linha contínua para a linha do Equador e os pólos, enquanto apenas utilizou uma linha contínua para representar o meridiano, possivelmente de Greenwich. Para Ausubel, Novak e Hanesian (1980) essa forma de representar alguns elementos do globo terrestre é basicamente uma associação simbólica primária para atribuir significado a símbolos isolados. Com relação à alternativa (b), 50\% da turma assinalaram que seriam linhas horizontais e verticais, entendendo ser o melhor modelo de representação da linha do Equador, meridianos e paralelos, demonstrando uma visão totalmente euclidiana. Por outro lado, 21,43\% dos estudantes optaram pela alternativa (c), entendendo que o modelo geométrico para ilustrar os itens sugeridos na questão seria por meio de circunferências.

\section{Questão 03}

3. Ao construir um triângulo no chão, qual é a soma das medidas dos seus ângulos internos? Desenhe a alternativa escolhida.
a) $180^{\circ}$
b) $270^{\circ}$
c) $90^{\circ}$
d) $100^{\circ}$ 


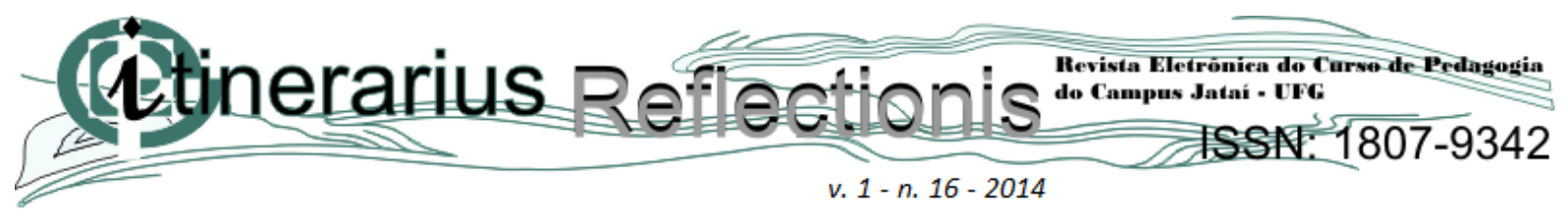

$\underline{\text { Análise }}$

O objetivo desta questão foi identificar se os estudantes conhecem uma das consequênciais dos postulados apresentados por Euclides de Alexandria no séc. III a.C. e estudado, nos bancos escolares no ensino fundamental. Esperávamos que os estudantes assinalassem a alternativa (a), porém apenas $21,43 \%$ da turma identificaram a alternativa correta. A estratégia desses estudantes para resolver este problema, partiu de uma divisão de um ângulo raso $\left(180^{\circ}\right)$ em três ângulos congruentes. Apesar da resposta correta, ficou evidente que os estudantes não apresentaram outras possibilidades para os ângulos internos de um triângulo cuja soma é $180^{\circ}$. A maioria dos estudantes na pesquisa, $(64,29 \%)$ entendeu que ao desenhar um triângulo no chão, a soma das medidas dos ângulos internos será igual a $270^{\circ}$ (b) (figura 3). Este resultado mostra uma ausência de conhecimento sobre triângulos e a relação com seus ângulos internos de acordo com os ensinamentos de Geometria, possivelmente explorados no ensino fundamental.

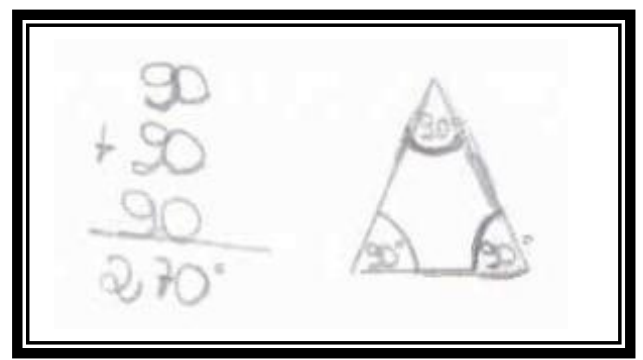

Figura 3: Protocolo do estudante 01 referente à soma dos ângulos internos de um triângulo construído no chão, referente a questão 03.

A alternativa (c) foi assinalada por 14,29\%, demonstrando desconhecimento com relação a construção de triângulos e a soma das medidas dos seus ângulos internos. Ocorrem também indícios da falta de significado para signos ou símbolos de conceitos para os estudantes. Por exemplo, o estudante (01) a representar um triângulo, demonstra fragilidade de aprendizagem conceitual sobre este símbolo em sua estrutura cognitiva. Ao colocar três ângulos internos iguais a $90^{\circ}$, desconsidera a definição para a soma dos ângulos internos de um triângulo euclidiano.

\section{Questão 04}

4. A sela é uma estrutura de suporte amarrada ao dorso de um animal de montaria como, por exemplo, cavalos e camelos. Ao construir um triângulo sobre esta estrutura: Desenhe a alternativa escolhida.

a) A soma dos ângulos internos será igual a $180^{\circ}$

b) Não é possível construir um triângulo

c) A soma dos ângulos internos será menor do que $180^{\circ}$

d) Os seus lados serão segmentos de reta. 


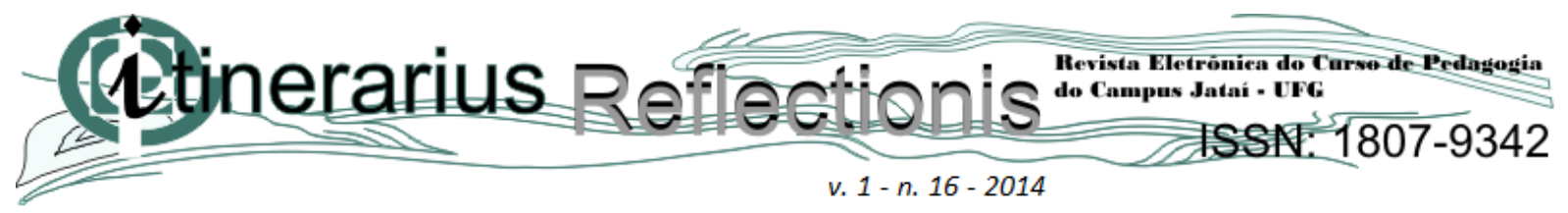

$\underline{\text { Análise }}$

Esta questão teve como objetivos identificar o que é uma sela (figura 4) e sua representação geométrica, bem como a construção de um triângulo sobre a superfície e o comportamento da soma de seus ângulos internos.

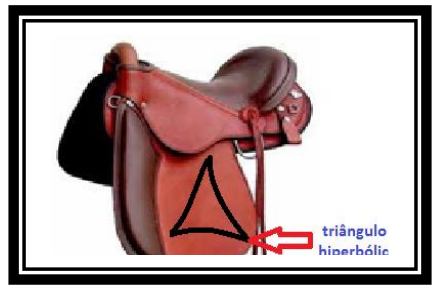

Figura 4: Sela de montaria, cuja geometria é comparada a hiperbólica. Fonte: www.marcalcouros.com.br

Esperávamos que os estudantes conseguissem representar este instrumento de montaria com um triângulo hiperbólico diferente dos triângulos que os estudantes estão acostumados a construir na sala de aula, porém sua construção ocorreu de maneira euclidiana, apresentada por segmentos de retas e algumas curvas (figura 5).

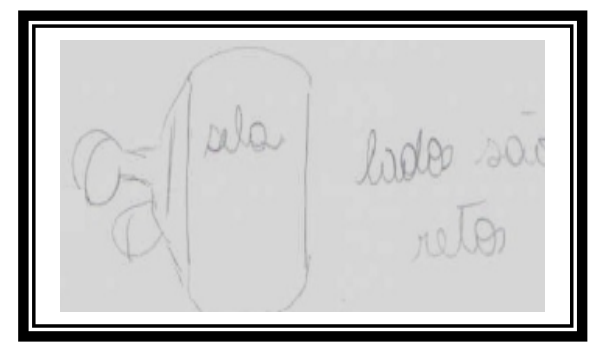

Figura 5 Protocolo do estudante 09 referente a construção de uma sela referente a questão 04.

Com relação às opções, esperávamos que os estudantes assinalassem a alternativa (c) onde neste tipo de geometria, a soma é menor do que dois ângulos retos, porém ficou constatado que apenas $21,43 \%$ dos estudantes acertaram, entretanto ao representar geometricamente o triângulo sob a sela, não apresentaram um modelo satisfatório ou convincente da opção escolhida, o que nos leva a pensar que eles arriscaram essa alternativa. A alternativa (b) se destacou nesta questão com $57,14 \%$, demonstrando o entendimento dos estudantes com a relação a construção de triângulos nesta superfície. Ficou constatado também que 21,43\% dos estudantes optaram pela alternativa (d), demonstrando a visão que os estudantes têm com relação à construção de triângulos, independente da superfície em estudo, onde os lados da figura serão sempre segmentos de reta e não curvas. Por fim nenhum estudante optou pela alternativa (a), creditado possivelmente ao fato do não reconhecimento de triângulos cuja soma de seus ângulos internos seja maior do que $180^{\circ} \mathrm{em}$ outras 


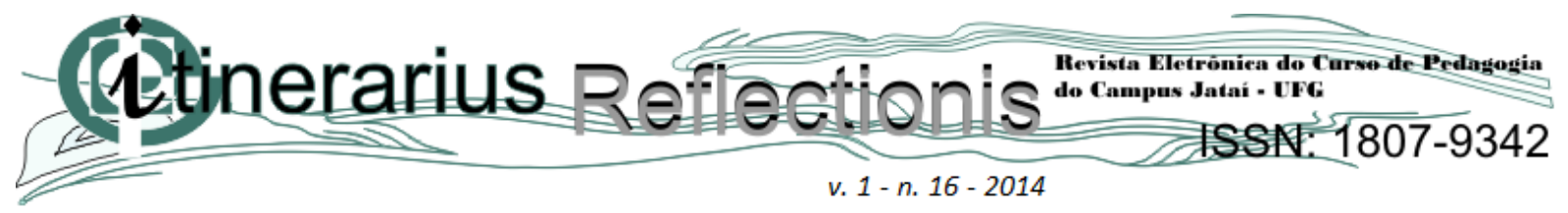

superfícies. A análise dessa questão demonstra que a maioria dos estudantes não possui de maneira clara, o conceito de triângulo hiperbólico muito menos uma organização em sua estrutura cognitiva, referente ao modelo representacional de um triângulo sobre a superfície elencada.

\section{Questão 05}

5. Você está olhando de uma praia para a linha divisória entre o céu e o mar, nesse momento um navio chega a esse ponto. Portanto:

a) Despencará, pois a Terra é plana.

b) Despencará pelo universo numa grande cachoeira.

c) Continuará sua viagem afirmando que existe mais mar.

d) Continuará, pois o mar é um grande lago plano infinito.

Desenhe a alternativa escolhida.

Esta questão teve como objetivo identificar como o estudante interpreta o modelo geométrico da Terra. Das alternativas propostas, somente duas foram assinaladas, (c) e (d), o que a priori demonstrou que os estudantes têm uma percepção de que a Terra não é uma superfície plana. Esperávamos que os estudantes assinalassem a alternativa (c), partindo da concepção que o planeta tem um modelo representativo em formato esférico conforme figura 6 a seguir e que a capacidade de visualização mesmo limitada, permite o entendimento acerca da continuidade do oceano, no entanto, $78,57 \%$ assinalaram a alternativa correta.

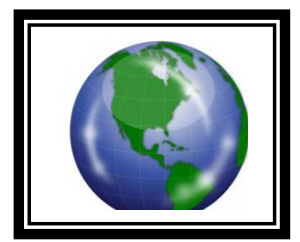

Figura 6: Planeta Terra, cujo modelo é representado pela Geometria Esférica.

Este índice alto pela alternativa (c) mostra que os estudantes conhecem intuitivamente outra geometria além da euclidiana, e que imaginar o planeta Terra como um plano, onde os navios desapareceriam não faz sentido para eles, levando a compreensão do porque a alternativa (a) não foi assinalada. Tal afirmação pode ser constatada a partir do espectro geométrico apresentado pelo estudante (14) (figura 7). 

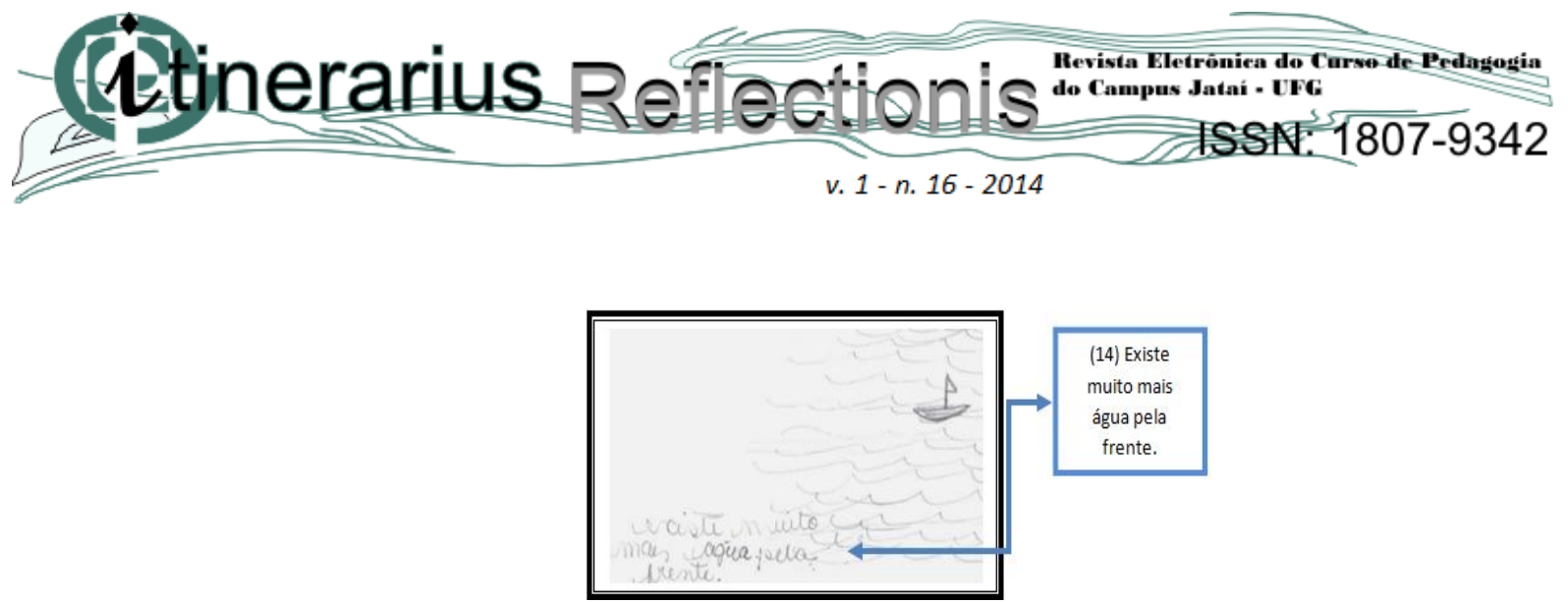

Figura 7: Protocolo apresentado pelo estudante 14, referente a compreensão do modelo geométrico do planeta Terra, representando a questão 05.

Com relação à alternativa (d), assinalada por $21,43 \%$ da turma, demonstrou que os estudantes possuem a percepção de continuidade do oceano advindos do modelo geométrico que representa o planeta, entretanto a compreensão que o mar é um grande lago "plano", demonstra a falta de conhecimento sobre a diferença entre lago e oceanos, provavelmente oriundos da ausência desses ensinamentos em Geografia no Ensino Médio. Com relação a palavra “plano”, identificou-se a presença da visão euclidiana, registrados por meio de desenhos sobre uma folha. O termo infinito não pode ser confundido com o termo limitado, porém os estudantes não conseguiram diferenciar estes conceitos, o que levou a escolha desta opção. A análise dessa questão demonstra que os estudantes não conseguiram estabelecer relações entre o conceito infinito e limitado e, portanto, há uma ausência de aprendizagem proposicional em suas estruturas cognitivas, bem como uma confusão na representação do modelo terrestre.

\section{Questão 01 (aberta)}

1. É possível ocorrer que um caçador ao partir de certo ponto da Terra, e andar $10 \mathrm{~km}$ para Sul, $10 \mathrm{~km}$ para Leste e $10 \mathrm{~km}$ para Norte, voltar ao ponto de partida? Justifique por meio de desenhos ou texto explicativo.

Os estudantes em geral construíram modelos geométricos e utilizaram registros escritos (figura 8), para justificar suas respostas ao problema. 

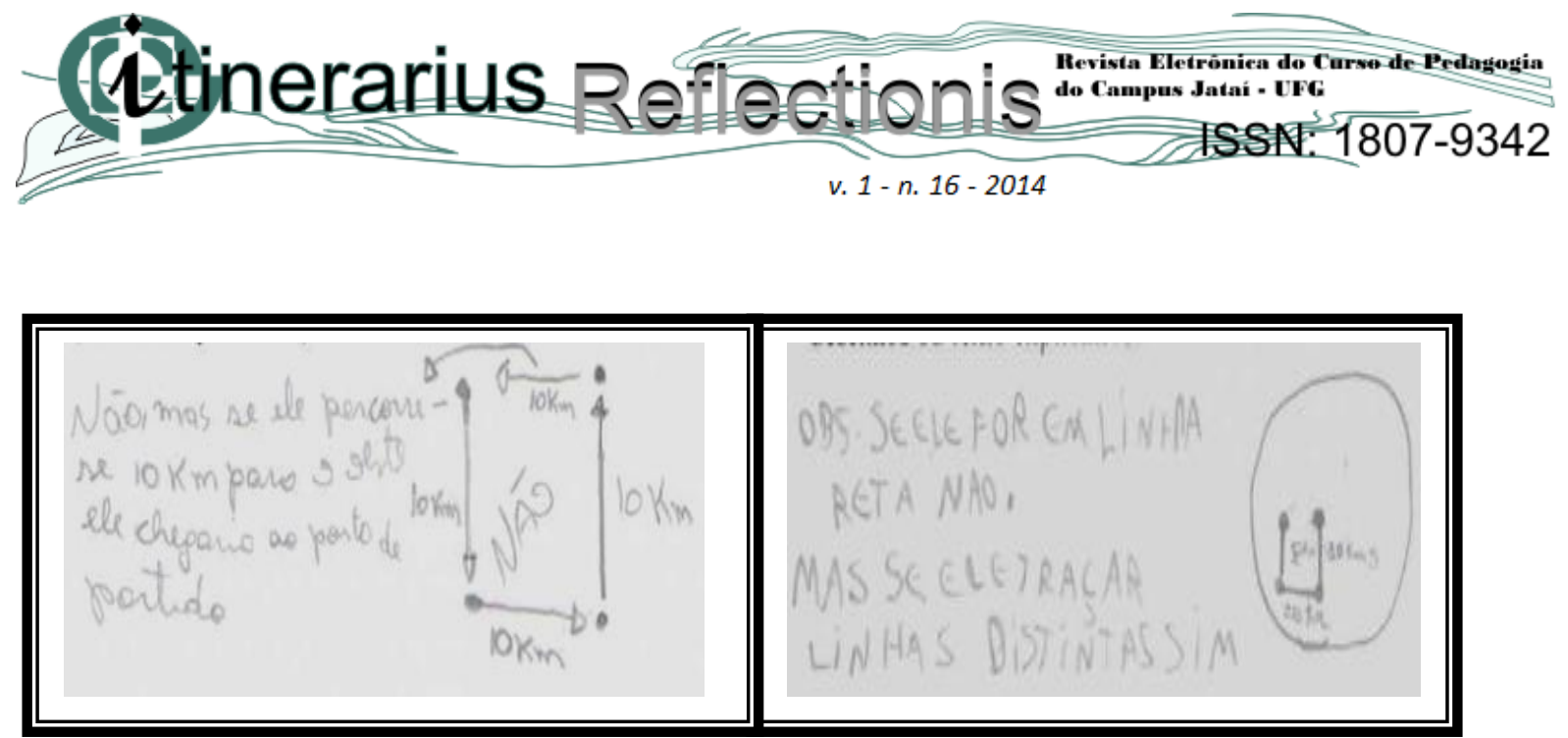

Figura 8: Protocolo dos estudantes 11 e 07, referente a solução geométrica apresentada para a questão aberta 01.

$\underline{\text { Análise }}$

A partir dos resultados obtidos, os registros transcritos elucidaram as estratégias utilizadas na solução do problema, emergindo as categorias de análise (Tabela 1):

Tabela 1: Categorias de análise construídas a partir dos registros dos estudantes referentes à questão aberta 01 (pré-teste).

\begin{tabular}{|c|c|}
\hline Categorias & Unidade de registro \\
\hline $\begin{array}{l}\text { Trajetória formada será } \\
\text { um triângulo } \\
\text { (visão euclidiana) }\end{array}$ & $\begin{array}{l}09 \text { - Ele vai andar em um triângulo. } \\
10 \text { - Voltará ao ponto de partida se o caminho for segmentos de reta, formando um triângulo. } \\
13 \text { - Sim e o caminho será um triângulo. } \\
03 \text { - Ela conseguirá voltar e seu caminho será um triângulo. }\end{array}$ \\
\hline $\begin{array}{l}\text { Trajetória formada por } \\
\text { arcos de círculo } \\
\text { (visão não euclidiana) }\end{array}$ & 05 - Para voltar ao ponto de partida, caminharia sobre um círculo. \\
\hline $\begin{array}{c}\text { Impossibilidade de } \\
\text { Solução }\end{array}$ & $\begin{array}{l}02 \text { - Acho que ele não voltará ao ponto de partida. } \\
08 \text { - Não conseguirá voltar. } \\
12 \text { - Não é possível ter solução este problema. } \\
04 \text { - Não poderá voltar. } \\
11 \text { - Não é possível a menos que haja uma alteração no problema. } \\
01 \text { - Não é possível existir tal solução. } \\
07 \text { - Não haverá possibilidade de solução. } \\
06 \text { - Acho que não poderia voltar, não tem como! } \\
14 \text { - Ele precisaria andar mais, portanto não tem como ele voltar. }\end{array}$ \\
\hline
\end{tabular}

Dos quatorzes estudantes, quatro $(28,57 \%)$ assinalaram que haveria solução, cujo caminho formaria um triângulo. É possível que a escolha por esta solução esteja condicionada a obrigatoriedade dos estudantes encontrarem geralmente uma resposta, característica do ensino de Matemática, e também por desconsiderarem as noções de pontos cardeais, conteúdos trabalhos no ensino de Geografia desde o nível fundamental. Nove estudantes $(64,28 \%)$ assinalaram que seria impossível retornar ao ponto de partida. Este grupo percebeu que numa superfície plana, de acordo 


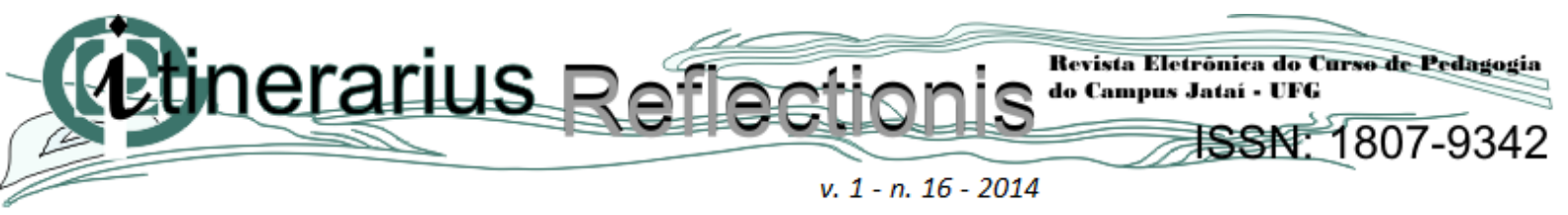

com os dados do problema, não é possível o caçador retornar ao ponto de origem, entretanto o problema situa o planeta Terra cuja geometria não é euclidiana (plana).

Apenas um estudante assinalou que é possível o caçador voltar ao ponto de partida cuja trajetória seria por arcos de círculo, indicando indícios de uma visão esférica para responder a questão. O estudante entendeu que, ao sair do pólo Norte e caminhar sobre os meridianos, haveria possibilidade de retorno, porém não levou em consideração a alternativa para o pólo Sul. Marquese (2006) lembra que o conhecimento de outras geometrias contribui para dar significado à Geometria de Euclides, no entanto, muitos estudantes apontaram uma desorganização conceitual, o que nos levar a pensar em uma estrutura cognitiva pobre. Por fim, foram identificados alguns subsunçores relevantes como "reta", "triângulo" e "círculo" que servirão de ancoragem para a inserção de conteúdos de Geometria Esférica e Hiperbólica.

\section{Questão 02 (aberta)}

2. Imagine que um caçador, resolveu sair de casa e caminhar em linha reta infinitamente.

a) Desenhe o caminho percorrido pelo caçador numa folha de papel.

b) De acordo com o caminho percorrido desenhado na folha de papel, é possível para o caçador voltar no ponto de partida?

c) Desenhe o caminho percorrido pelo caçador numa bola de isopor.

d) De acordo com o caminho percorrido desenhado na bola de isopor, é possível para o caçador voltar ao ponto de partida?

e) Anote suas conclusões.

Os estudantes em geral construíram modelos geométricos e utilizaram registros escritos (figura 9), para justificar suas respostas ao problema.

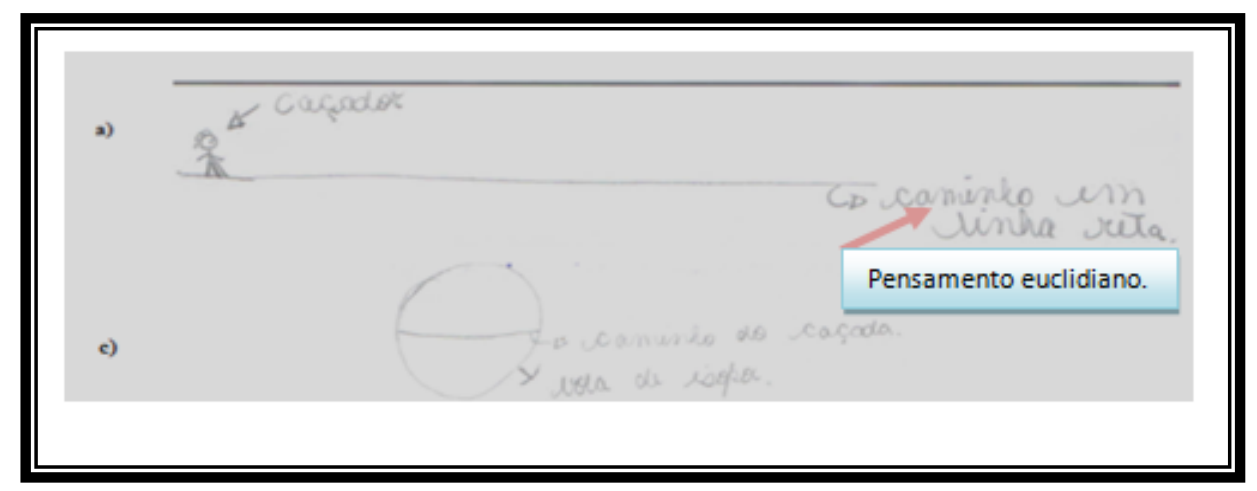

Figura 9: Protocolo apresentado pelo estudante 14, referente à solução geométrica fornecida a questão aberta 02. 


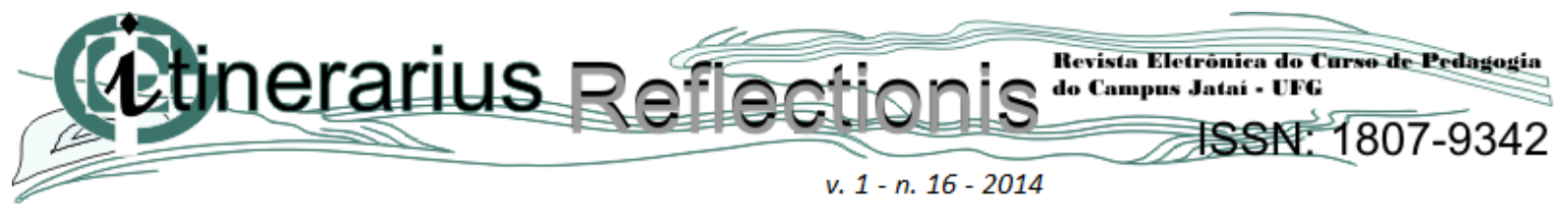

$\underline{\text { Análise }}$

A partir dos resultados obtidos, os registros transcritos elucidaram as estratégias utilizadas na solução do problema, emergindo as categorias de análise (Tabela 3):

Tabela 2: Categorias de análise construídas a partir dos registros dos estudantes referentes à questão aberta 02 (pré-teste).

\begin{tabular}{|c|c|}
\hline Categorias & Unidade de registro \\
\hline $\begin{array}{l}\text { Entendeu que é possível } \\
\text { caminhar infinitamente } \\
\text { em linha reta e retornar } \\
\text { ao ponto de partida. } \\
\text { (visão euclidiana) }\end{array}$ & $\begin{array}{l}14 \text { - Eu acho que ele conseguiria voltar ao ponto de partida se caminhasse em linha } \\
\text { reta, basta saber qual é o seu ponto de partida. } \\
12 \text { - Ele conseguiria, basta ir deixando marcas no caminho. } \\
11 \text { - Sim, basta ele passar pelo mar. } \\
04 \text { - Ele vai andar em linha reta e vai chegar ao ponto de partida } \\
03 \text { - Se ele for em linha reta ele saberá voltar ao ponto de partida. } \\
06 \text { - Sim, é possível se ele voltar pelo caminho correto em linha reta. } \\
08 \text { - Minha conclusão é que se ele seguir sempre em linha reta ele fará a volta na } \\
\text { Terra e voltará ao seu destino inicial. } \\
09 \text { - Sim ele pode voltar por onde ele foi basta dar meia volta. } \\
10 \text { - Sim é possível voltar de onde partiu se o caminho for em linha reta. }\end{array}$ \\
\hline $\begin{array}{c}\text { Entendeu que não é } \\
\text { possível caminhar } \\
\text { infinitamente em linha } \\
\text { reta e retornar ao ponto } \\
\text { de partida. } \\
\text { (visão não euclidiana) }\end{array}$ & $\begin{array}{l}\text { 01 - Não, pois a folha é um plano e não teria como, porém no isopor é possível. } \\
13 \text { - Na folha não tem como voltar ao ponto de partida, já na bola de isopor já é } \\
\text { possível. } \\
07 \text { - Notoriamente não será possível na folha de papel. } \\
02 \text { - Na bola de isopor, ele voltará ao ponto de partida, ele vai caminhar e chegará ao } \\
\text { mesmo lugar, já na folha de papel, ele irá caminhar em linha reta então não voltará no } \\
\text { ponto de partida. } \\
05 \text { - Não é possível voltar ao ponto de partida, só se eu dobrar a folha, em linha reta } \\
\text { não dá. }\end{array}$ \\
\hline
\end{tabular}

A partir dos dados coletados, esperávamos que os estudantes respondessem que o caminho percorrido pelo caçador "seria curvo", justificando o fato que a Terra tem forma arredondada, porém, dos quatorzes estudantes, nove $(64,28 \%)$ assinalaram que é possível caminhar infinitamente em linha reta e retornar ao ponto de partida, fato este teoricamente relacionado com conhecimentos cristalizados de Geometria Euclidiana, onde a menor distância entre dois pontos é dada por um segmento de reta, o que aponta para uma confusão conceitual entre "reta" e "esfera". Mesmo afirmando que seria possível retornar ao ponto de partida, os estudantes associaram o caminho percorrido pelo caçador à uma linha reta, esquecendo que na superfície geométrica que vivemos para grandes distâncias não existem retas, mas arcos de círculos máximos (curvas). Essa ausência de aprendizagem representacional demonstra que o estudante ainda memoriza modelos geométricos para aplicar na resolução de exercícios, sem realizar uma reflexão acerca do problema, o que 


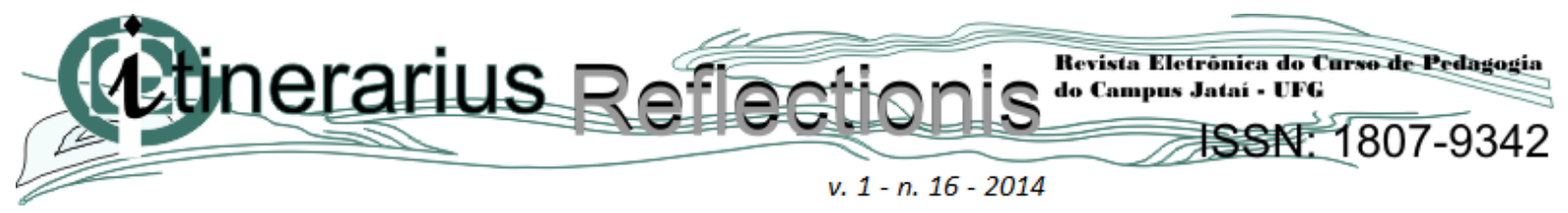

Ausubel caracteriza como aprendizagem mecânica. Com relação à utilização de material concreto (bola de isopor), esperávamos que construíssem círculos, consequentemente haveria possibilidade do caçador retornar ao ponto de onde saiu, concluindo assim que a trajetória não seria uma reta, contudo houve estudantes que não conseguiram perceber que a trajetória seria uma curva, demonstrando uma fragilidade à aprendizagem representacional e conceitual, que segundo Ausubel, Novak e Hanesian (1980) revela a importância e a necessidade de organizar o pensamento, atribuindo significado lógico e psicológico aos conhecimentos que foram construídos e estruturados idiossincraticamente.

\section{Questão 03 (aberta)}

3. Seja bem vindo estudante! Vocês agora é parte da tripulação do navio LOBARIEMAN. A sua missão é encontrar uma coleção de artefatos da coroa que, há muitos anos, esteve escondido em Fernando de Noronha, Brasil. Para não levantar suspeita sobre as atividades da marinha brasileira você partirá da ilha de Florianópolis, capital de Santa Catarina. Essa missão exige o Máximo de sigilo e precisão.

a) Para a tripulação LOBARIEMAN chegar a Fernando de Noronha, como você acha que será o percurso percorrido?

b) Em Geometria, qual a figura que você usaria para representar esse percurso?

c) Como você representaria no papel a situação a) e b)?

Os estudantes em geral construíram modelos geométricos e utilizaram registros escritos (figura 10), para justificar suas respostas ao problema.

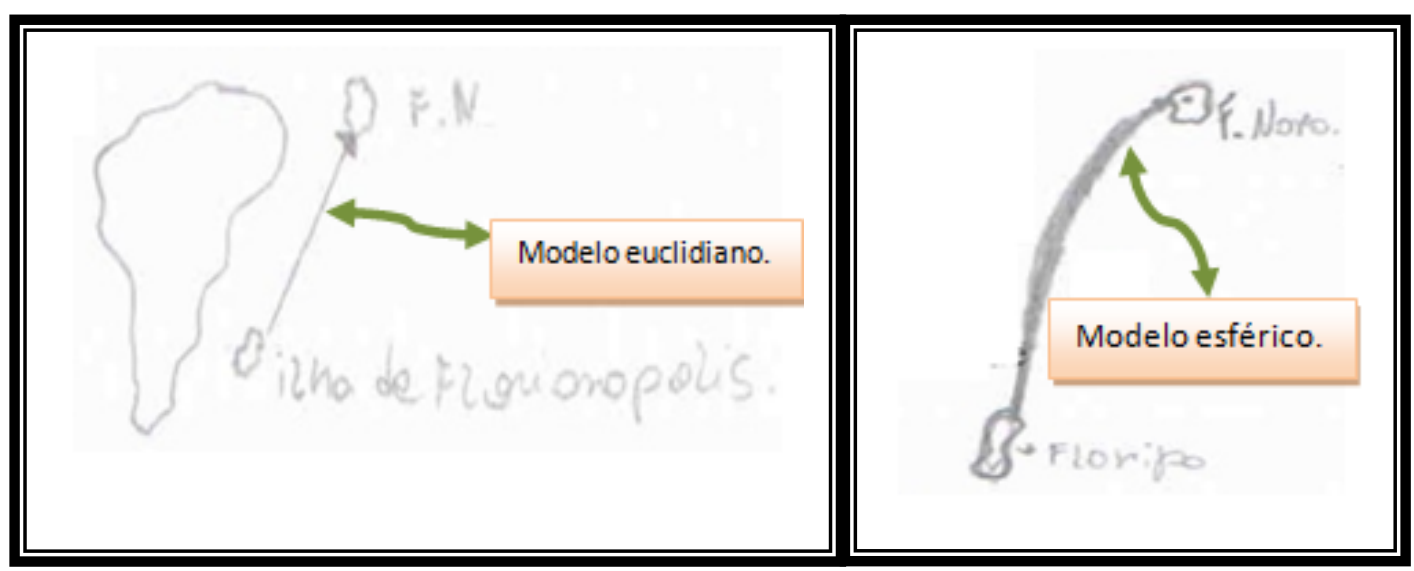

Figura 10: Protocolo dos estudantes 04 e 11, apresentando o modelo geométrico de saída de Florianópolis com destino à Fernando de Noronha, apresentada para a questão aberta 03. 


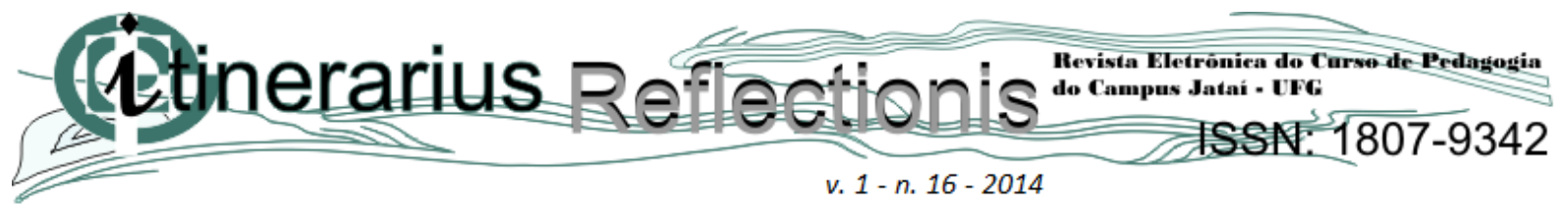

$\underline{\text { Análise }}$

A partir dos resultados obtidos, os registros transcritos elucidaram as estratégias utilizadas na solução do problema, emergindo as categorias de análise (Tabela 3):

Tabela 3: Categorias de análise construídas a partir dos registros dos estudantes referentes à questão aberta 03 (pré-teste).

\begin{tabular}{|c|c|}
\hline Categorias & Unidade de registro \\
\hline $\begin{array}{l}\text { Reconheceu percurso } \\
\text { curvilíneo como solução } \\
\text { (visão não euclidiana) }\end{array}$ & $\begin{array}{l}14 \text { - Teria que fazer uma curva para chegar até a outra ilha. } \\
11 \text { - Faria uma linha curvada. } \\
12 \text { - A trajetória seria uma curva. } \\
07 \text { - Será uma curva tal trajeto. }\end{array}$ \\
\hline $\begin{array}{l}\text { Reconheceu percurso } \\
\text { retilíneo como solução } \\
\text { (visão euclidiana) }\end{array}$ & $\begin{array}{l}01 \text { - Chegaria em linha reta. } \\
13 \text { - A trajetória é uma reta. } \\
06 \text { - Será feita em linha reta. } \\
08 \text { - Mesmo longe chegaria em linha reta. } \\
05 \text { - De Florianópolis a Fernando de Noronha, será em linha reta. } \\
04 \text { - Por um submarino em linha reta. } \\
09 \text { - Levará varias horas, mas chegará se for em linha reta. }\end{array}$ \\
\hline Não apresentou solução & $\begin{array}{l}03 \text { - Não sei qual será a resposta, mas será sigiloso. } \\
10 \text { - ??? Não sei. } \\
02 \text { - Não sei. }\end{array}$ \\
\hline
\end{tabular}

Esta questão teve vários objetivos como: verificar se os estudantes sabem localizar as ilhas de Fernando de Noronha e Florianópolis; representar a trajetória percorrida pela tripulação que seria uma curva e conceituar que o modelo ideal para representar a distância entre as ilha seria um arco de circunferência, porém apenas quatro estudantes $(28,57 \%)$ conseguiram identificar corretamente as ilhas, representar a trajetória e apresentar o conceito de curva. Havia uma expectativa na afirmação que a menor distância entre dois pontos seria um segmento de reta, confirmada por sete estudantes (50\%), mostrando que de fato estes percebem o mundo que vive de modo plano. Três estudantes $(21,42 \%)$ não apresentaram solução, possivelmente por não reconhecer a localização da ilha de Fernando de Noronha, local raramente abordado nas aulas de Geografia.

A análise evidencia que os conceitos geométricos estabelecidos na literatura específica são apresentados para os estudantes em sua forma final e acabada, fato que não contribui para que eles construam seus conhecimentos. Há indícios de que, da forma como estão posto as percepções dos estudantes para a trajetória entre as ilhas, esse modelo encontra-se cristalizado como uma aprendizagem por recepção mecânica. 


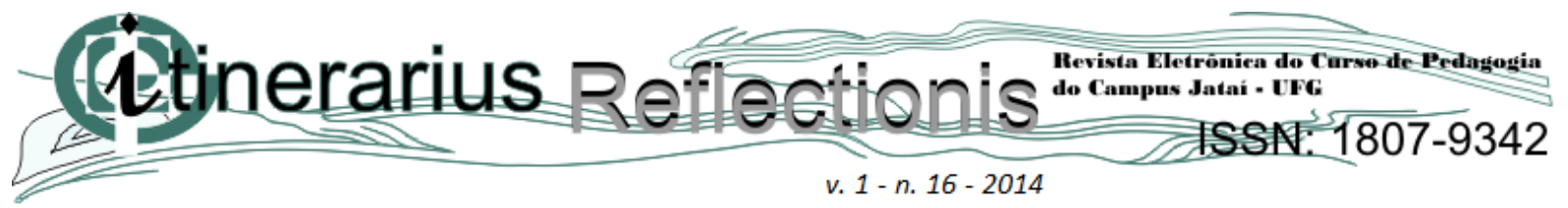

\section{Questão 04 (aberta)}

4. Imagine que um avião saia de São Paulo com destino a New York e percorre aproximadamente oito mil quilômetros. Se o avião resolvesse realizar a viagem em linha reta, o que aconteceria com esse avião?

Esta questão buscou identificar como os estudantes compreendiam a situação de um avião realizar uma trajetória retilínea saindo de São Paulo com destino a New York. Foi eleito um registro (figura 11) a seguir com o objetivo de justificar suas respostas ao problema

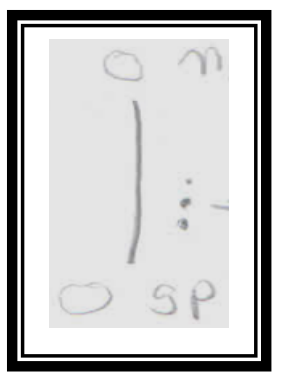

Figura 11: Protocolo do estudante 03, demonstrando geometricamente a trajetória do avião com saída de São Paulo com destino a Nova York.

$\underline{\text { Análise }}$

A partir dos resultados obtidos, os registros transcritos elucidaram as estratégias utilizadas na solução do problema, emergindo as categorias de análise (Tabela 4):

Tabela 4: Categorias de análise construídas a partir dos registros dos estudantes referentes à questão aberta 04 (pré-teste).

\begin{tabular}{|c|c|}
\hline Categorias & Unidade de registro \\
\hline $\begin{array}{l}\text { Utilizou o modelo curvilíneo } \\
\text { (visão não euclidiana) }\end{array}$ & $\begin{array}{l}14 \text { - Ele iria bater talvez sofrer turbulências, necessitando realizar algumas curvas para } \\
\text { chegar ao destino. } \\
12 \text { - Se percorrer em linha reta não chegará, portanto precisa realizar trajetória em forma de } \\
\text { curvas. } \\
13 \text { - Ele não voaria em linha reta, seria preciso mudar o percurso, ou seja, utilizando curvas. }\end{array}$ \\
\hline $\begin{array}{l}\text { Utilizou de modelo retilíneo } \\
\text { (visão euclidiana) }\end{array}$ & $\begin{array}{l}10 \text { - Este avião iria chegar ao seu destino, não aconteceria nada. } \\
04 \text { - Ele chegaria do mesmo jeito, ele vai em linha reta. } \\
06 \text { - Acho que não aconteceria, ele iria de São Paulo até New York em linha reta. }\end{array}$ \\
\hline $\begin{array}{l}\text { Não chegará ao seu destino } \\
\text { (impossibilidade de solução) }\end{array}$ & $\begin{array}{l}08 \text { - O avião sairá de percurso e não chegará a New York. } \\
03 \text { - Ele irá cair. } \\
05 \text { - Vai cair. } \\
01 \text { - Ele chegará somente até o oceano, portanto não chegará. } \\
11 \text { - Ele vai pousar no mar, portanto não chegará. } \\
09 \text { - Não vai chegar ao seu destino. } \\
07 \text { - Os passageiros não chegariam ao destino, pois o avião iria em linha reta saindo da } \\
\text { Terra. }\end{array}$ \\
\hline
\end{tabular}




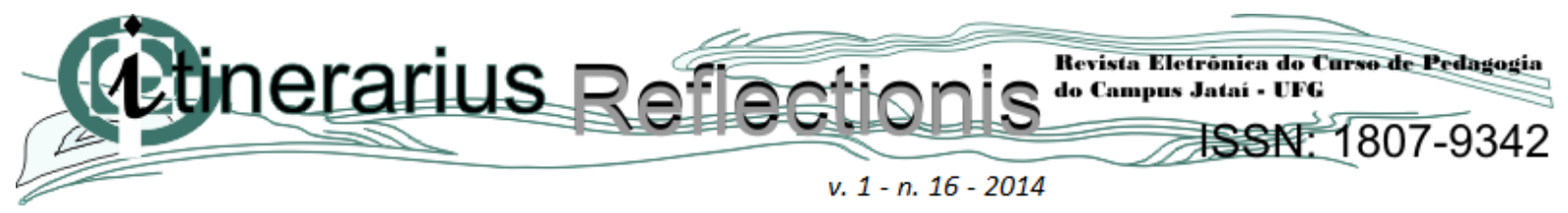

Esta questão buscou identificar como os estudantes visualizam a trajetória do avião e que conclusões chegariam após ter percorrido oito mil quilômetros em linha reta. Esperávamos que, se o avião deixasse de acompanhar a curvatura do planeta Terra, sua trajetória seria uma reta tangente ao globo terrestre, portanto, se perderia no espaço ou seria destruído pela gravidade, porém (50\%) da turma entenderam que o avião cairá ou que não chegaria ao destino. Três estudantes $(21,42 \%)$ compreenderam que o avião chegaria ao destino sem problemas, caso sua trajetória fosse uma reta. Também foi constatado que três estudantes $(21,42 \%)$ responderam que o avião chegaria ao destino, caso sua trajetória fosse constituída por curvas, percepção adequada para a situação proposta. Apenas um estudante $(7,14 \%)$ não apresentou resposta ao problema. Nessa questão, as evidências mostram que os estudantes em geral não conseguiram utilizar de outros modelos geométricos além do euclidiano para resolver à problemática. Diante desse cenário, já desconfiávamos que qualquer avaliação que aplicássemos antes da realização da sequência didática, poderia nos trazer um indicador do déficit de aprendizagem em Geometria presente nos sujeitos da investigação.

\section{CONSIDERAÇÕES FINAIS}

A Geometria em geral é considerada como o alicerce essencial da Matemática, porém como é abordada nas escolas atualmente, por meio de problemas descontextualizados, por métodos de repetição, sem relacionar com o seu cotidiano, parece não manifestar nos alunos grande interesse para apropriar-se desse conhecimento. A inexistência de uma abordagem sobre o ensino de Geometria não Euclidiana no ensino médio evidencia que os professores, em geral, negligenciam os conhecimentos cotidianos dos estudantes ou seguem a metodologia de um determinado livro didático como fonte única de conhecimento, mostrando assim, a fragilidade de um sistema de ensino que privilegia resultados abstratos, propedêuticos e sem relação com o cotidiano do estudante.

Os professores em geral têm dificuldade de compreensão de seu conteúdo, acentuados pelo desconhecimento de linhas metodológicas ou, ainda, pela ausência de textos nos livros didáticos que contemplem o assunto. Este trabalho inicial visou contribuir para diminuir estas dificuldades no ensino de Geometria não Euclidiana nas escolas em geral. Sob o olhar da aprendizagem de Geometria, os alunos têm acentuadas dificuldades em resolver problemas envolvendo conceitos geométricos, de representar, interpretar e solucionar situações do cotidiano por meio de modelos 


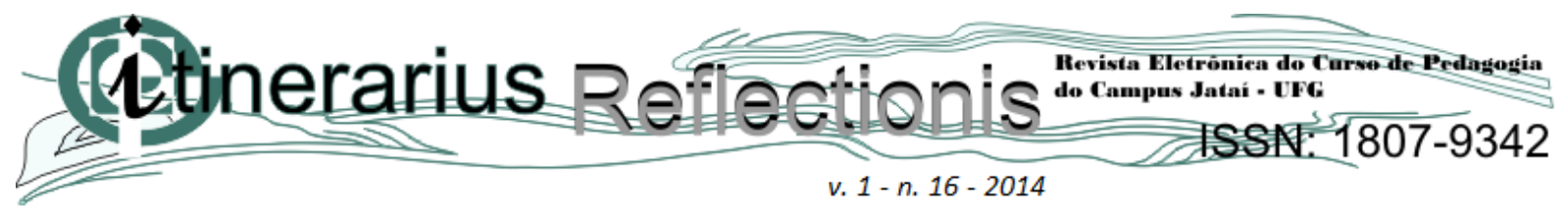

geométricos, direcionando o estudo de Geometria para uma memorização. Entretanto uma abordagem da Geometria não Euclidiana nos bancos escolares é possível, possibilitando ao estudante uma nova visão para interpretar o mundo que o governa, para compreender que muitos elementos da natureza são explicados por geometrias consistentes e diferentes da Geometria Euclidiana, que o conhecimento geométrico permite a descrição e representação de forma organizada do mundo que vive, proporcionando assim, uma abordagem por meio de uma linguagem mais concisa e universal.

Em geral a análise do pré-teste leva a inferir que os estudantes possuem alguns conhecimentos prévios (subsunçores relevantes) presentes em sua estrutura cognitiva acerca de conceitos de Geometria Esférica e Hiperbólica. Os estudantes utilizaram seus conhecimentos de Geometria Euclidiana com o objetivo de resolver os problemas e apresentaram algumas dificuldades de aprendizagem conceitual, representacional e proposicional relativo ao tema Geometria. Assim, a utilização de textos e vídeos como organizadores prévios ganham importância na apresentação do novo conteúdo, pois, de acordo com Ausubel, Novak e Hanesian (1980), caso isso não ocorra, as novas informações possivelmente não serão aprendidas significamente. A intenção principal é criar uma ligação sólida entre aquilo que se conhece e o que se pretende aprender. Não é possível, segundo Novak e Gowin (1996) para o estudante alcançar altos níveis de aprendizagem significativa antes que as estruturas cognitivas adequadas sejam construídas, e assim o processo de aprendizagem deve ser interativo ao longo do tempo, para que se possa alcançar o domínio do conhecimento ao nível de um especialista no assunto.

\section{REFERÊNCIAS}

ALVES, S. (2008). Geometria Não Euclidiana. São Paulo: IME-USP: material para oficina; Semana da Licenciatura.

AUSUBEL, D.P; NOVAK, J.D.; HANESIAN, H. (1980). Psicologia Educacional. Rio de Janeiro: Interamericana.

BOYER, C.B. (2009). História da Matemática. $2^{\text {o }}$ ed. São Paulo: Blücher.

BONGIOVANI, V. (2010). De Euclides às geometrias não euclidianas. Revista Iberoamericana de Educación Matemática. São Paulo, v.1, n. 22, p. 37-51.

BRASIL. Secretaria de Educação Fundamental. (1998). Parâmetros curriculares nacionais: matemática. Brasília: MEC/SEF. 


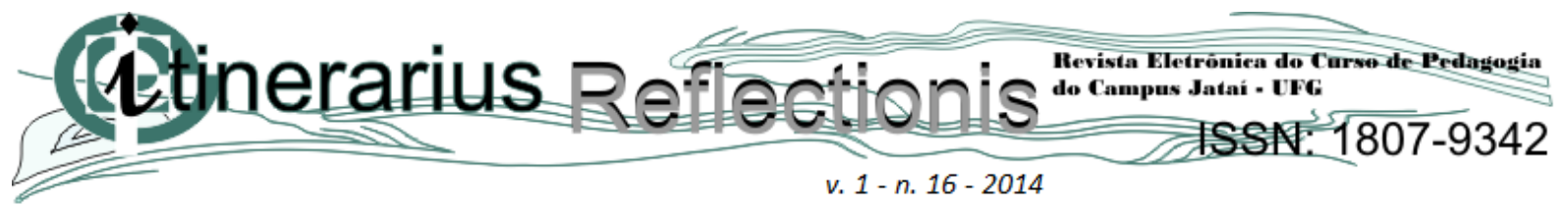

CABARITI, E. (2006). A geometria hiperbólica na formação docente: possibilidades de uma proposta com o auxílio do cabri-géomètre. III Seminário Internacional de Pesquisa em Educação Matemática, São Paulo.

CARVAlHO, Maria Aparecida da Silva de; CARVAlHO, Ana Márcia Fernandes Tucci de Carvalho (2011). O ensino de geometria não euclidiana na educação básica. In: XIII Conferência Interamericana de Educação Matemática, Recife.

CEDREZ, A.J.P. (2012). Construcción, necessidad e intuición de essência em geometria. Scientia \& Studia. São Paulo, v. 7, n. 4, p. 595-617.

KALEFF, A.M. (2004). Desenvolvimento de Atividades Introdutórias ao Estudo das Geometrias não Euclidianas: Atividades Interdisciplinares para Sala de Aula e Museus Interativos. In: Congresso Brasileiro de Extensão Universitária, n. 2. Belo Horizonte.

LEIVAS, J.C. P. (2012). Educação geométrica: reflexões sobre ensino e aprendizagem em geometria. Revista SBEM-RS, Porto Alegre, no. 13, v.1, p. 9-16.

EVES, H. (2008). Introdução à história da Matemática. São Paulo: Unicamp.

MARQUEZE, J. P. (2006). As faces dos sólidos platônicos na superfície esférica: uma proposta para o ensino-aprendizagem de noções básicas da geometria esférica. 162 f. Dissertação (Mestrado)-Pontifícia Universidade Católica de São Paulo, São Paulo, SP.

MARTOS, Z.G. (2002). Geometrias não euclidianas: uma proposta metodológica para o ensino de Geometria no Ensino Fundamental. Rio Claro, 143f. Dissertação (Mestrado em Educação Matemática)-Instituto de Geociências e Ciências exatas, Universidade Estadual Paulista.

MLODINOW, L. (2010). A janela de Euclides: a história da geometria, das linhas paralelas ao hiperespaço. São Paulo: Geração.

MOREIRA, M. A. (2010). Mapas conceituais e aprendizagem significativa. São Paulo: Centauro. MOREIRA, M.A.; MASINI, E. F. S. (2001). Aprendizagem significativa: A teoria de David Ausubel. São Paulo: Centauro.

NOVAK, J.D.; GOWIN, B. D. (1996). Aprender a Aprender. Lisboa: Plátano Edições Técnicas. 